\title{
$\beta$-Catenin/Tcf signaling in murine oocytes identifies nonovulatory follicles
}

\author{
Macalister Usongo ${ }^{1}$, Aida Rizk ${ }^{1}$ and Riaz Farookhi ${ }^{1,2,3}$ \\ ${ }^{1}$ Department of Experimental Medicine, McGill University, Montreal, Quebec, Canada, ${ }^{2}$ Department of Obstetrics \\ and Gynecology, F344 Royal Victoria Hospital, McGill University, 687 Pine Avenue West, Montreal, Quebec, \\ Canada H3A 1 A1 and ${ }^{3}$ Department of Physiology, McGill University, Montreal, Quebec, Canada
}

Correspondence should be addressed to M Usongo who is now at Department of Obstetrics and Gynecology, F344 Royal Victoria Hospital, 687 Pine Avenue West, Montreal, Quebec, Canada H3A 1A1; Email: macalister.usongo@mail.mcgill.ca

\begin{abstract}
WNTS are secreted glycoprotein molecules that signal through one of three signaling pathways. The best-characterized pathway involves stabilization of the multifunctional protein $\beta$-catenin, which in concert with members of the T-cell factor (Tcf) family activates specific gene transcription. We have examined putative $\mathrm{Wnt} / \beta$-catenin in the murine ovary using transgenic mice harboring a reporter construct that activates $\beta$-galactosidase (lacZ) expression in response to $\beta$-catenin/Tcf binding (TopGal mice). Primordial and primary follicles did not stain for lacZ, and the proportion of $\beta$-catenin/Tcf signaling oocytes was lower than that of nonsignaling oocytes throughout estrous cycle. $\beta$-Catenin/Tcf signaling oocytes were observed in follicles from the secondary stage of development and their proportion increased with follicular maturation (secondary follicles, $20 \%$; early antral and antral follicles, $70 \%$ ). In contrast, the majority ( $>\mathbf{9 0} \%$ ) of ovulated oocytes did not stain for lacZ. As the oocyte possesses components for WNT signal transduction, our data suggest that $\beta$-catenin/Tcf signaling is involved in the development of follicular ovulatory capability and identifies nonovulatory follicles.

Reproduction (2012) $\mathbf{1 4 4} 669-676$
\end{abstract}

\section{Introduction}

The follicle is the functional unit of the ovary serving to protect and nourish the oocyte. Ovarian follicles and their contained oocytes are committed to either development or atresia once a third layer of granulosa cells is formed (Oakberg 1979). Folliculogenesis begins with recruitment of germ cells into a pool of primordial follicles that will later progress through the primary, secondary, antral, and then preovulatory follicle stages (Guigon \& Magre 2006). Follicular maturation is controlled by regulatory mechanisms orchestrated by several factors including the pituitary gonadotropins FSH and LH (Richards 1994); intraovarian growth regulatory factors such as insulin-like growth factors, EGF, TGF $\alpha$, TGF $\beta$, and bFGF (Gougeon 1996); and steroids such as estradiol ( $E_{2}$; Edson et al. 2009). Additional locally produced factors belonging to the TGF $\beta$ superfamily such as activins, inhibins, follistatin (Knight \& Glister 2001), as well as oocyte-derived factors including GDF9 and BMP15 (Matzuk 2000), are also required at different stages of follicular development. Throughout life, follicles are recruited from the primordial follicle pool for further growth and development in a continuous manner. By puberty (6-week-old in mice), increases in circulating FSH during each reproductive cycle recruit a cohort of antral follicles (McGee \& Hsueh 2000). This cyclic recruitment of follicles (estrous cycle) in rodents can be divided into four stages (proestrus, estrus, metestrus, and diestrus) characterized by hormonal and physiological changes (Byers et al. 2012). In the absence of gonadotropin stimulation, the follicles (and oocyte) degenerate.

During oogenesis and folliculogenesis, the oocyte acquires a normal morphology, an ability to resume and complete meiosis, initiate, and sustain embryonic development (Krisher 2004). Only a subset of oocytes is capable of supporting meiosis, fertilization, and early embryo development to the blastocyst stage and the proportion of these competent oocytes increases with follicular size (Mermillod et al. 2008). The developmental competence of oocytes increases in parallel with follicular size (Marchal et al. 2002). Although meiosis and early development may be completed successfully, there are a variety of other processes occurring within the oocyte that are required for complete developmental competence (Krisher 2004).

The WNTS comprise a large family of secreted cysteine-rich glycoprotein molecules (Miller 2002). WNTS transduce their signal through one of three signaling pathways, of which the best characterized, the WNT/B-catenin pathway, leads to an increase in 
intracellular $\beta$-catenin protein that acts as a co-transcription factor with members of T-cell factor (Tcf)/lymphoid enhancer (Lef) family of transcription factors to drive target gene expression (Behrens et al. 1996). WNTS are involved in a number of developmental processes including establishment of cell fate, proliferation, and differentiation (Wodarz \& Nusse 1998, Logan \& Nusse 2004, Cadigan 2008). The WNT signaling pathway has been implicated in ovarian development. Ovaries of Wnt4 knockout mice are abnormal, containing structures similar to testicular tubules and exhibiting dramatically reduced oocyte numbers (Vainio et al. 1999, Boyer et al. 2010). Early in embryonic development, WNT4/5a signaling coordinates germ cell entry into meiosis (Naillat et al. 2010). Multiple WNT signaling pathway genes are expressed within the oocyte (Wang et al. 2004, Zheng et al. 2006). In addition to Wnt4, sex-specific expression within the gonad has been found for Wnt5a, Wnt6, and Wnt9a (Cederroth et al. 2007). While WNTS play a key role in embryonic development of the ovary (Vainio et al. 1999, Yao et al. 2004, Ottolenghi et al. 2007), several studies described the expression of WNT signaling components in adult rodent ovaries (Hsieh et al. 2002, 2003, 2005, Ricken et al. 2002, Kimura et al. 2006, Harwood et al. 2008). Furthermore, several molecules needed for activation of alternative WNT pathways are in place during oocyte growth (Harwood et al. 2008). These studies collectively suggest that the WNT signaling pathway may play a role in follicle (and oocyte) development.

Given the complex expression pattern of WNT signaling components in oocytes, it is important to assess whether $\beta$-catenin/Tcf-mediated expression can serve as an informative marker for oocyte quality and its ability to be ovulated. We have assessed canonical WNT signaling in the murine ovary using transgenic mice (TopGal) harboring a reporter construct that activates $\beta$-galactosidase (lacZ) expression in response to $\beta$-catenin/Tcf binding (Mohamed et al. 2004). We provide evidence suggesting that $\beta$-catenin/Tcf signaling in oocytes identifies nonovulatory follicles.

\section{Results \\ $\beta$-Catenin/Tcf-activated lacZ expression is seen in oocytes of growing follicles}

To begin to explore $\beta$-catenin/Tcf signaling activity in oocytes, we processed ovaries from transgenic mice during postnatal development for X-gal staining. Histological examination of sections at postnatal day 1 ( $\mathrm{P} 1$; Fig. 1A), P12 (Fig. 1B), P21 (Fig. 1C), and in cycling (Fig. 1D) mice demonstrated $\beta$-galactosidase (lacZ) staining in oocytes (Fig. 1B, C and D, black arrowhead) and granulosa cells of some growing follicles (Fig. 1E). LacZ-positive cells were also observed within corpus luteum of cycling mice (Fig. 1F). The fallopian tube/ uterus served as positive control for $\beta$-galactosidase staining (Fig. 1G). Although lacZ staining levels were not uniform, a follicle was designated lacZ-positive only when partial or full staining of the oocyte was observed. Primordial and primary follicles did not stain and no distribution pattern was observed for lacZ-positive follicles within the ovary.

\section{The proportion of lacZ-positive follicles is lower than lacZ-negative follicles at all stages of estrous cycle}

Hormonal regulation of WNT signaling pathway components has been detected in rodent ovaries. Wnt4
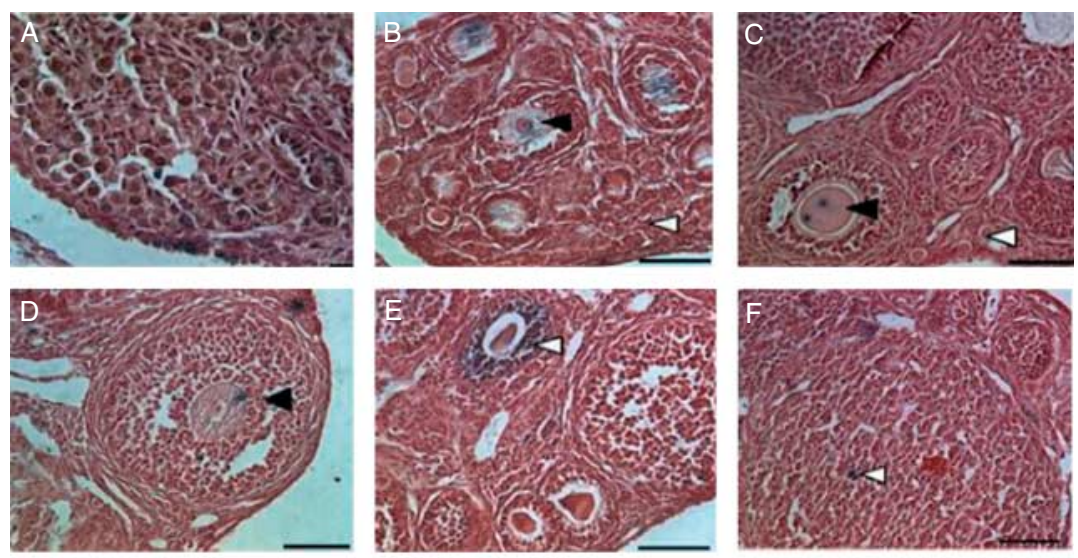

Figure $1 \beta$-Catenin/Tcf-mediated signaling is activated in growing oocytes during postnatal development. Ovaries were stained for $\beta$-galactosidase activity, sectioned, and counterstained with H\&E. At postnatal day 1 (P1), no $\beta$-galactosidase activity is seen in oocytes (A). Blue staining was detected specifically in oocytes from the secondary stage of follicular development at P12 (B), P21 (C), and in cycling mice (D) (black arrowhead). Primordial follicles did not stain for lacZ (white arrowhead, B and C). Only some growing follicles demonstrated staining of granulosa cells (white arrowhead, E). Within the corpus luteum, not all luteal cells stained for lac $Z$ (white arrowhead, F). Fallopian tube $\beta$-galactosidase staining served as positive control (G). Scale bar $=50 \mu \mathrm{m}$. 
expression is elevated in response to human chorionic gonadotropin (hCG) and highly expressed in corpora lutea (Hsieh et al. 2002). To explore the possibility that hormones regulate $\beta$-catenin/Tcf signaling in oocytes, we examined lacZ expression in oocytes during the estrous cycle. The data set compiled for this study included follicles of one ovary from a pair of ovaries of cycling mice ( $n=4$ for diestrus; $n=5$ for proestrus, estrus, and metestrus). We observed that the proportion of lacZ-positive follicles was significantly lower than lacZ-negative follicles at all stages of estrous (Fig. 2; $P<0.05)$.

\section{$\beta$-Catenin/Tcf signaling is increasingly activated in occytes as the follicle matures}

Intraovarian factors that regulate early follicular development remain unknown. Once started, the initiation of follicular growth is continuous throughout life and occurs daily irrespective of hormonal status of the animal. We examined whether changes in follicular diameter due to growth and maturation are related to $\beta$-catenin/ Tcf-mediated lacZ expression in oocytes. Measurements obtained for follicular diameter were stratified according to the phase of estrous cycle. LacZ-positive follicles were significantly larger than lacZ-negative follicles at all stages of estrous cycle (Fig. 3a; $P<0.05$ ).

Because follicular growth passes through distinct stages defined by certain structural characteristics, we examined whether $\beta$-catenin/Tcf-mediated expression in oocytes is associated with specific stages of follicular development. The majority $(>70 \%)$ of secondary follicles did not stain for lacZ (Fig. 3b; $P<0.05$ ). On the contrary, we observed an increase in the proportion of stained to unstained follicles at the early antral stage.

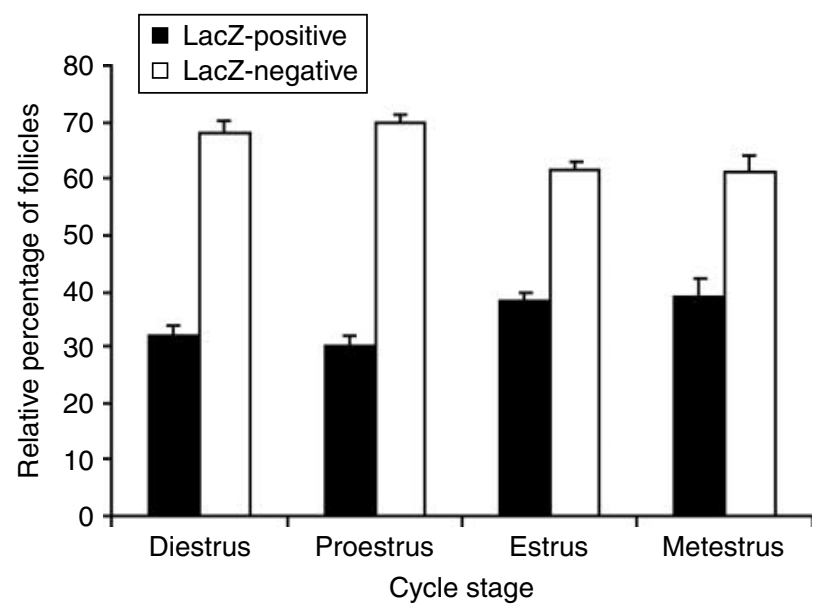

Figure 2 The percentage of lacZ-positive follicles is lower than lacZnegative follicles at all stages of estrous cycle. Mean percentage of lacZ-positive follicles at different stages of estrous cycle. Data presented as mean \pm S.E.M.
At least $70 \%$ of early antral follicles stained for lac Z (Fig. 3c; $P<0.05$ ). The scarcity of antral follicles within the ovary prompted us to group antral follicles from individual ovaries of representative stages of estrous into a single group. Using this approach, we observed that $\sim 60 \%$ of antral follicles stained for lacZ.

\section{$\beta$-Catenin/Tcf signaling oocytes are larger than nonsignaling oocytes}

Oocytes in primordial follicles remain unchanged for shorter or longer periods of time in the ovary until they are recruited. We investigated the relationship between oocyte size and $\beta$-catenin/Tcf signaling activity. Oocyte diameter was stratified according to stages of estrous cycle in the same manner as with follicular diameter. Statistical comparison revealed a significant difference between lacZ-positive and lacZ-negative oocytes. LacZpositive follicles were larger than lacZ-negative oocytes at all phases of estrous (Fig. $4 ; P<0.05$ ).

\section{Gonadotropin stimulation increases the proportion of lacZ-positive oocytes in antral follicles of prepubertal mice}

To study the direct effects of FSH and hCG on $\beta$-catenin/Tcf-mediated lacZ expression in oocytes, superovulation experiments using pregnant mare's serum gonadotrophin (PMSG) and hCG were done in prepubertal mice. In nonstimulated mice, lacZ-positive oocytes were observed in approximately equal proportions of preantral and antral follicles (57 and 43\% respectively). $\beta$-Catenin/Tcf-mediated lacZ staining in antral follicles increased $48 \mathrm{~h}$ following PMSG treatment (preantral, 32\%; antral, 68\%), and this was further enhanced $24 \mathrm{~h}$ after hCG treatment (preantral, 20\%; antral, $80 \%$ ). In contrast, the majority ( $>90 \%$ ) of oocytes recovered from the oviducts did not stain for lacZ.

\section{Ovulated oocytes do not stain for lacZ}

To determine the reproductive consequence of $\beta$-catenin/Tcf signaling activity, we examined ovulated oocytes for lac Z expression. For these experiments, a total of 110 oocytes were recovered from oviducts ( $n=14$ mice) on the morning of estrus and examined for lacZ expression. The majority of oocytes recovered $(91.8 \%)$ did not stain for lacZ and these were $\sim 80.2$ $\pm 0.55 \mu \mathrm{m}$ in diameter (mean \pm S.E.M.; $n=11$ ). These oocytes (lacZ-negative) had an intact cumulus mass (left panel, Fig. 5a) representing fully grown oocytes derived from Graafian follicles. Approximately $2 \%$ lacZ-negative ovulated oocytes were fragmented and $6 \%$ had reduced cumulus mass. On the contrary, cumulus-oocyte complexes in which the oocyte stained for lacZ were smaller and contained few cells (right panel Fig. 5a). 

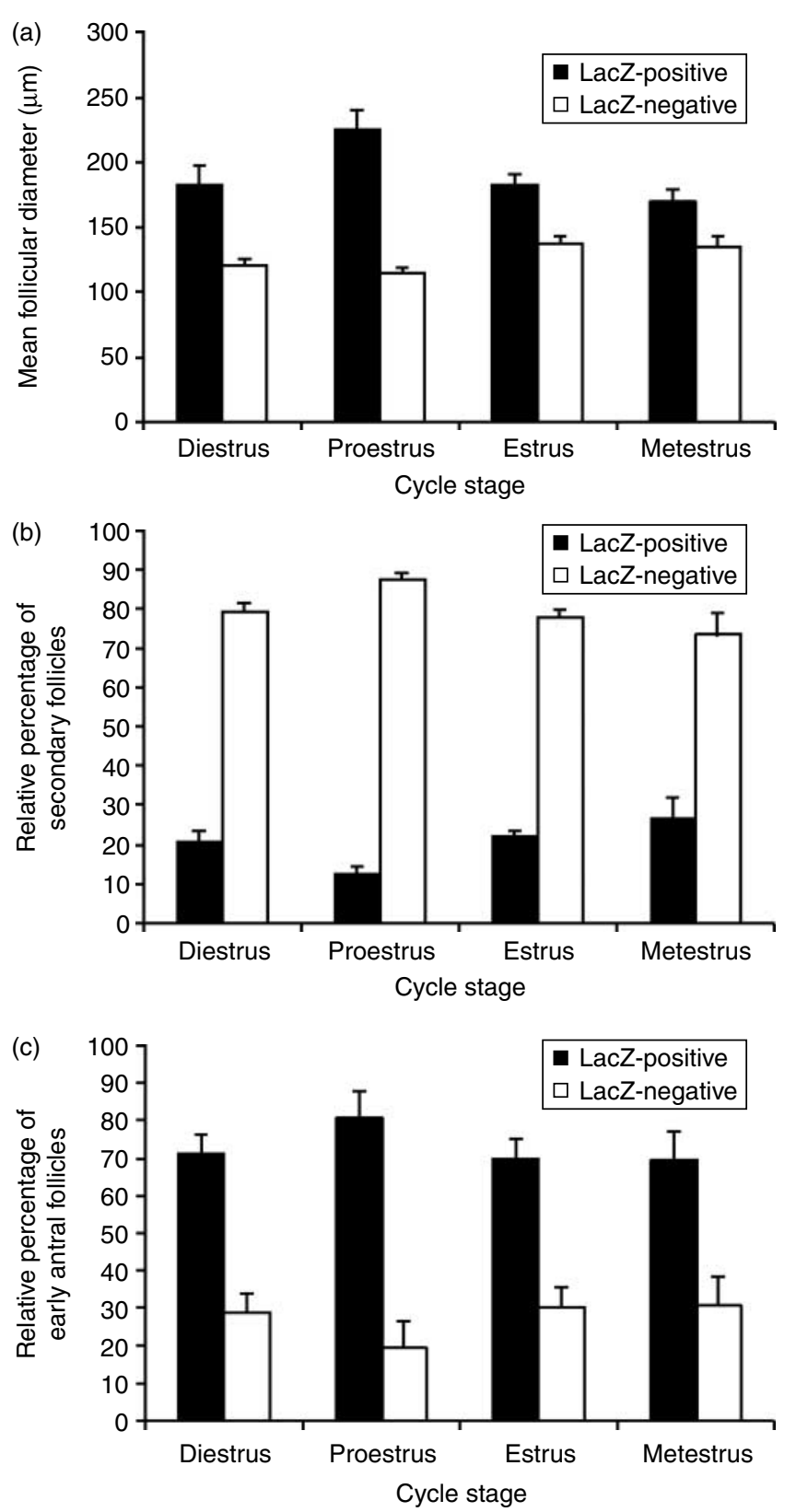

Figure 3 The proportion of lacZ-positive follicles increases with follicular growth and maturation. (a) Average diameter of lacZ-positive and lacZ-negative follicles at all stages of estrous cycle. LacZ-positive follicles are larger in diameter than lacZ-negative follicles $(P \leq 0.05)$. Data presented as mean \pm s.E.M. ( $n=4-5$ ovaries). (b) The percentage of stained and unstained secondary follicles at all stages of the estrous cycle. A higher proportion ( $>70 \%$ ) of secondary follicles did not stain for lacZ throughout estrous. Values are presented as mean \pm s.E.M. (c) The percentage of lacZ-positive and lacZ-negative early antral follicles at all stages of the estrous cycle. Majority early antral follicles $(>70 \%)$ stained for lacZ. Values are the mean \pm S.E.M.

Approximately $33 \%$ of these lacZ-positive oocytes were fragmented (Fig. 5b). A few (two out of nine total) ovulated lacZ-positive oocytes were similar in size and morphology to nonstained oocytes.

\section{Discussion}

This study has revealed spatiotemporal $\beta$-catenin/ Tcf-mediated expression in oocytes during follicular development. The proportion of lacZ-positive oocytes was lower than lacZ-negative oocytes throughout the estrous cycle. LacZ-positive follicles were larger than lacZ-negative follicles and the proportion of stained to unstained follicles increased with follicular maturation. Despite a higher proportion of oocytes in antral follicles staining for lacZ, most ovulated oocytes did not show any indication of active WNT signaling.

In this study, we examined $\beta$-catenin/Tcf-mediated lacZ expression in oocytes as a readout for canonical WNT signaling. Detection of $\beta$-galactosidase activity in oocytes from the secondary stage of follicular development suggests that canonical WNT signaling is inactive during primordial follicular formation. This is in agreement with a previous study indicating that $\beta$-catenin/Tcf signaling is transcriptionally inactive in developing germ cells (Chassot et al. 2008). In accordance with our results, Kimura et al. (2006) have shown that canonical Wnt molecules are expressed at low levels in primordial germ cells and overexpression of $\beta$-catenin impairs germ cell development.

Recent evidence indicates that depleting $\beta$-catenin in granulosa cells of growing and pre-ovulatory follicles does not cause any overt effects in follicular development, ovulation, or luteinization (Fan et al. 2010). The reason(s) why some granulosa and luteal cells, but not all, stain for lacZ remains to be elucidated. Even when $\beta$-catenin and its binding partner Lef are abundantly present in the cell nucleus, $\beta$-catenin/Lef- 1 complexes do not always activate reporter gene expression (Prieve \& Waterman 1999). The lack of $\beta$-catenin/Tcf-mediated lacZ staining in all granulosa and luteal cells suggests that $\beta$-catenin/Tcf signaling is not absolutely necessary in adult ovarian follicular cell growth and differentiation.

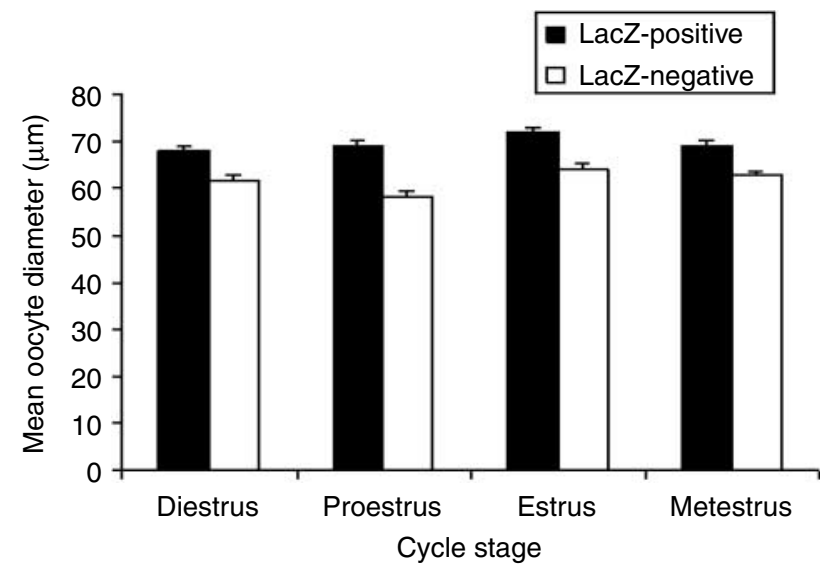

Figure 4 LacZ-positive oocytes are larger than lacZ-negative oocytes at all phases of estrus cycle $(P \leq 0.05)$. The average diameter of lacZpositive and lacZ-negative oocytes at the four stages of estrous cycle. Data presented as mean \pm S.E.M. $(n=4-5$ ovaries). 
(a)

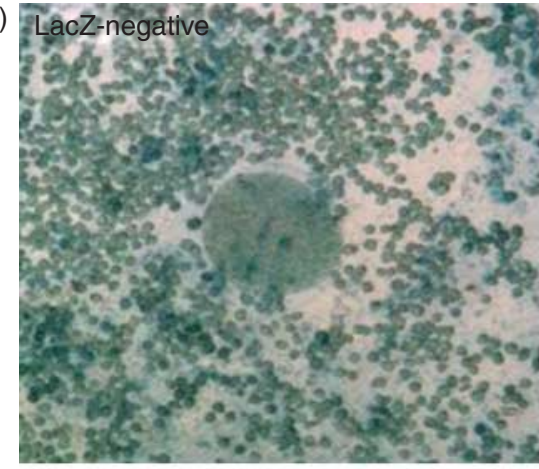

(b)

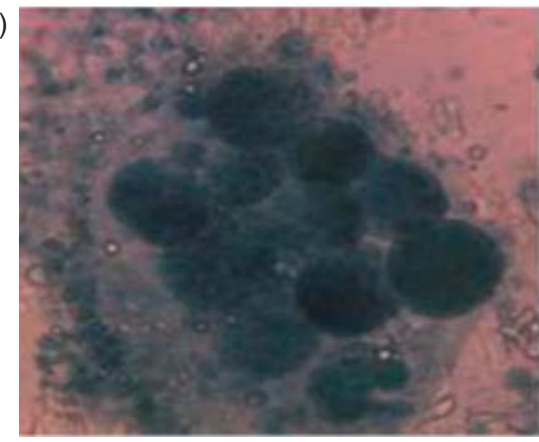

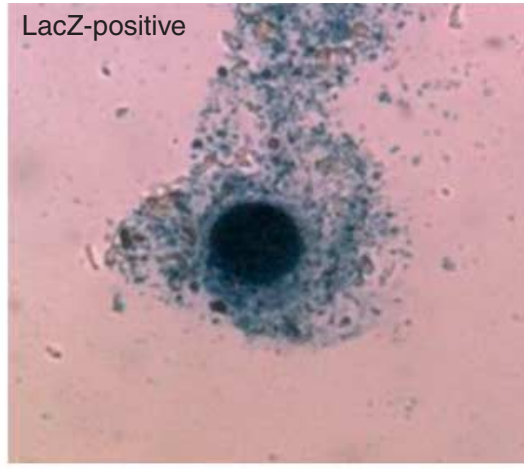

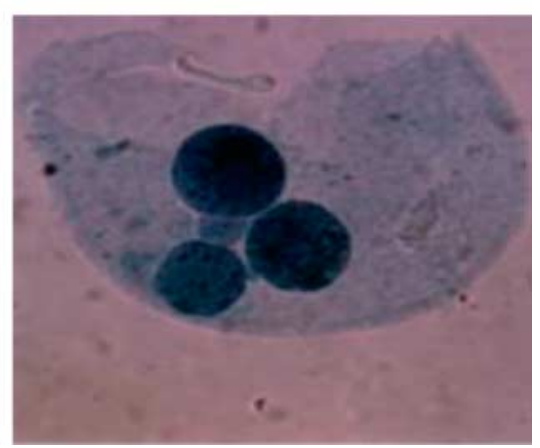

Figure 5 Ovulated oocytes do not show $\beta$-galactosidase activity and are morphologically normal. (a) Representative light microscopic image of lacZ-negative and lacZ-positive cumulus-oocyte complex. LacZ-negative oocytes had an intact cumulus mass representing fully grown and developmentally normal oocytes. (b) Representative light microscopic image of fragmented lacZ-positive oocytes. Note the different levels of oocyte fragmentation.
That majority of ovarian follicles do not show $\beta$-catenin/Tcf signaling during the estrous cycle was probably because most follicles were in the primary and secondary stages of follicular development and as such did not express lacZ. We noted that the proportion of lacZ-positive follicles increased with antrum formation (secondary follicles, $\sim 20 \%$; early antral and antral, $\sim 70 \%$ ), suggesting that $\beta$-catenin/Tcf-mediated gene expression in oocytes is initiated once a secondary follicle is formed and increases with follicular maturation. In addition, we observed a remarkable increase in the diameter of lacZ-positive follicles at proestrus. These observations may be explained by rapid follicular growth that is known to result from increased $E_{2}$ levels at this time. This event is likely the result of proestrus FSH surge (Hirshfield \& Midgley 1978).

As $\beta$-catenin/Tcf signaling activity is seen in oocytes of juvenile and prepubertal mice, our data suggest that activation of $\beta$-catenin/Tcf signaling in oocytes is independent of pituitary gonadotropins. It is possible that other factors associated with regulation of follicular growth, maturation, and differentiation activates $\beta$-catenin/Tcf signaling in oocytes. The increased proportion of lacZ-positive antral follicles following hormone treatment suggests that PMSG drives follicular maturation and $\beta$-catenin/Tcf-mediated lacZ activity in oocytes. Given that only lacZ-negative oocytes were ovulated, their expulsion from the ovary probably led to the observed increase in lacZ-positive follicles seen after hCG treatment. However, oocyte $\beta$-catenin/ Tcf-mediated lacZ activity in hCG-treated mice is unlikely due to rising progesterone levels as progesterone is known to inhibit WNT/ $\beta$-catenin signaling by induction of $D K K 1$ and FOXO1 (Wang et al. 2010).

The diameter of an oocyte is often used as a marker for maturity or meiotic competence (Blanco et al. 2011). For this reason, one can infer that $\beta$-catenin/Tcf signaling is activated in oocyte once it has reached a certain maturation state. The observation that ovulated oocytes did not stain for lac Z raises the possibility that a developmental defect exist within the follicle that precludes ovulation of lacZ-positive oocytes. This defect may be within the oocyte or follicle. It has been demonstrated that over-activation of $\beta$-catenin negatively affects $\mathrm{LH}$-induced ovulation and luteinization (Fan et al. 2010). It is also known that disruption of pituitary LH synthesis, LH receptor binding, or its downstream signaling pathways blocks ovulation and luteinization (Elvin \& Matzuk 1998). The failure of lacZpositive oocytes to ovulate suggests impaired responses to $\mathrm{LH}$ and reduced expression of genes required for ovulation and cumulus expansion. Work by Antosik et al. (2010) suggests that the morphology of cumulusoocyte complex is associated with oocyte quality and fertilization ability. Interestingly, the fact that ovulated lacZ-positive oocytes showed anomalies in size and shape reinforces the idea that $\beta$-catenin/Tcf signaling pathway identifies developmentally incompetent oocytes. There is accumulating evidence indicating that $\beta$-catenin is involved in apoptosis (Kim et al. 2000) and that apoptosis is responsible for fragmentation of murine oocytes (Takase et al. 1995). Cytoplasmic fragmentation of ovulated lacZ-positive oocytes suggests that these oocytes were undergoing apoptosis. 
In summary, our study indicates that the canonical WNT signaling pathway is active in oocytes from the secondary stage of follicular development. The proportion of $\beta$-catenin/Tcf-mediated lacZ-positive follicles increased with follicular maturation. Upon ovulation, $>90 \%$ oocytes recovered from oviducts did not stain for lacZ. As the oocyte and granulosa cells possess components for WNT signal transduction, our results suggests that canonical WNT signaling may be involved in the development of follicular ovulatory capability and identifies nonovulatory follicles. Our findings may have clinical and animal biotechnological application related to assisted reproductive technologies. Identification of markers in follicles/oocytes that are correlated with developmental competence will increase efficiency of in vitro embryo production.

\section{Materials and Methods}

\section{Animals}

All animal procedures followed guidelines established by the Canadian Council of Animal Care and approved by the Animal Care Committee of the Royal Victoria Hospital, McGill University. CD1 mice bearing the $\beta$-catenin/Tcf-responsive lacZ reporter gene (TopGal mice) have been previously described (Mohamed et al. 2004). Female and male CD1 mice homozygous for the transgene were provided for colony establishment by Dr Daniel Dufort (Department of Obstetrics and Gynecology, McGill University, Montreal, Canada).

\section{Estrus cycle determination}

The stage of estrus cycle was determined by cytological evaluation of vaginal smears as described previously (Hong et al. 2010). Sterile PBS was gently flushed into the vagina using glass pipettes between 0900 and $1100 \mathrm{~h}$ daily. The lavages were smeared on glass slides and examined microscopically in unstained wet preparations. The following criteria were used for identification of cycle stage: proestrus, nucleated cells; estrus, cornified cells; metestrus, leukocytes and cornified cells; and diestrus, leukocytes.

\section{Collection and preparation of tissues}

Mice were killed by cervical dislocation. Both left and right ovaries from each mouse were collected, washed in PBS (137 mM NaCl, $2.7 \mathrm{mM} \mathrm{KCl}, 8 \mathrm{mM} \mathrm{Na} \mathrm{HPO}_{4}$, and $2 \mathrm{mM}$ $\mathrm{KH}_{2} \mathrm{PO}_{4}, \mathrm{pH} 7.4$ ), and fixed for 5-15 min in freshly prepared $4 \%$ paraformaldehyde (PFA) in PBS. After rinsing in wash buffer (PBS containing $2 \mathrm{mM} \mathrm{MgCl} 2,0.1 \%$ Triton, $0.05 \%$ sodium deoxycholate), gonads were stained in the dark overnight at $37^{\circ} \mathrm{C}$ in wash buffer supplemented with $1 \mathrm{mg} / \mathrm{ml} \mathrm{X}$-gal, $0.04 \%$ $\mathrm{N}, \mathrm{N}$-dimethylformamide, $5 \mathrm{mM}$ potassium ferricyanide, and $5 \mathrm{mM}$ potassium ferrocyanide to disclose $\beta$-galactosidase activity (Iglesias et al. 2007). After being stained, gonads were washed in PBS and processed for histology.

\section{Histology}

X-gal-stained ovaries were postfixed in 4\% PFA overnight at room temperature, rinsed in PBS, embedded in paraffin for sectioning (7- $\mu \mathrm{m}$ thick), and standard counterstaining with hematoxylin and eosin.

\section{Quantification of follicles}

Follicles were classified according to the criteria as detailed in Myers et al. (2004) into three main groups: secondary, early antral, and antral follicles. The total number of follicles was estimated by applying the nucleator and fractionator principle described by Gundersen (2002). Oocyte nuclear number was equated to follicular number. The number of follicles was estimated by counting oocytes with large visible nuclei. The percentage of lacZ-positive and lacZ-negative oocytes was estimated from the total number of follicles per ovary determined.

\section{Follicle and oocyte measurements}

Every sixth ovarian section was evaluated for the presence of oocytic follicles using a Leica DM IL microscope equipped with four, ten, 20, and 40 times magnification plan objectives (Leica Microsystems, Wetzlar, Germany). The microscope was fitted with a Hamamatsu ORCA ER digital camera (Hamamatsu Photonics, Shizuoka, Japan) driven by MetaMorph Software (Universal Imaging Corporation, Downingtown, PA, USA). Captured images of follicles meeting the selection criteria described earlier for quantification of follicles were saved as tiff-formatted images and transferred to Image J Software (NIH, Bethesda, MD, USA). The accurate calculation of diameters was ensured using the measuring tools in the Image J Software. Additionally, when measuring diameters, two measurements were taken. The second measurement originated at a right angle from the midpoint of the first measurement. The two measurements were averaged and expressed as the diameter of the structure. Data were collected in this manner to determine the diameters of the follicle and oocyte. Follicular diameters were measured from the basement membrane of the ovarian follicle. The diameter of the oocyte was measured excluding the zona pellucida.

\section{Collection of oocytes}

Sexually mature mice were examined daily for estrus. Oviductal tissue including oocytes were collected $(n=14$ mice) after detection of estrus and processed for X-gal. Oocytes were collected by flushing the oviduct and examined for $\beta$-galactosidase activity.

\section{Hormone stimulation and follicular estimation}

Prepubertal (21- to 26-day-old) mice were injected i.p. with PBS or $5 \mathrm{IU}$ PMSG followed $48 \mathrm{~h}$ later with $5 \mathrm{IU}$ hCG. PMSG and hCG were purchased from the National Hormone and Peptide Program (Torrance, CA, USA). Ovaries were recovered $48 \mathrm{~h}$ after treatment with PBS or PMSG and $24 \mathrm{~h}$ after injection 
with hCG. In the case of hCG treatment, ovulated oocytes were recovered from the oviducts. Ovaries were fixed, sectioned $(7 \mu \mathrm{m})$, and processed for X-gal staining. Every fifth ovarian section was evaluated and only follicles in which the oocyte germinal vesicle and nucleolus were visible were considered.

\section{Statistical analysis}

Data were analyzed using SYSTAT 10.2 Statistical Software (SYSTAT Software, Richmond, CA, USA). ANOVA was used with Tukey's test in the post hoc analysis for cell counts to ascertain group mean differences. Data are presented as mean \pm s.E.M. $P \leq 0.05$ was considered significant.

\section{Declaration of interest}

The authors declare that there is no conflict of interest that could be perceived as prejudicing the impartiality of the research reported.

\section{Funding}

This study was funded by grants from the Canadian Institutes of Health Research (CIHR) and a Mcgill University Health Centre-Research Institute (MUHC-RI) fellowship to M Usongo.

\section{References}

Antosik P, Kempisty B, Jackowska M, Bukowska D, Lianeri M, Brussow KP, Wozna M \& Jaskowski JM 2010 The morphology of porcine oocytes is associated with zona pellucida glycoprotein 3 and integrin $\beta 2$ protein levels. Veterinarni Medicina 55 154-162.

Behrens J, von Kries JP, Kuhl M, Bruhn L, Wedlich D, Grosschedl R \& Birchmeier W 1996 Functional interaction of $\beta$-catenin with the transcription factor LEF-1. Nature 382 638-642. (doi:10.1038/ 382638a0)

Blanco MR, Demyda S, Moreno MM \& Genero E 2011 Developmental competence of in vivo and in vitro matured oocytes: a review. Biotechnology and Molecular Biology Review 6 155-165.

Boyer A, Goff AK \& Boerboom D 2010 WNT signaling in ovarian follicle biology and tumorigenesis. Trends in Endocrinology and Metabolism 21 25-32. (doi:10.1016/j.tem.2009.08.005)

Byers SL, Wiles MV, Dunn SL \& Taft RA 2012 Mouse estrous cycle identification tool and images. PLOS ONE 7 e35538. (doi:10.1371/ journal.pone.0035538)

Cadigan KM 2008 Wnt- $\beta$-catenin signaling. Current Biology 18 R943-R947. (doi:10.1016/j.cub.2008.08.017)

Cederroth CR, Pitetti JL, Papaioannou MD \& Nef S 2007 Genetic programs that regulate testicular and ovarian development. Molecular and Cellular Endocrinology 265-266 3-9. (doi:10.1016/j.mce.2006.12.029)

Chassot AA, Ranc F, Gregoire EP, Roepers-Gajadien HL, Taketo MM, Camerino G, de Rooij DG, Schedl A \& Chaboissier MC 2008 Activation of $\beta$-catenin signaling by Rspo1 controls differentiation of the mammalian ovary. Human Molecular Genetics 17 1264-1277. (doi:10.1093/hmg/ddn016)

Edson MA, Nagaraja AK \& Matzuk MM 2009 The mammalian ovary from genesis to revelation. Endocrine Reviews 30 624-712. (doi:10.1210/er. 2009-0012)

Elvin JA \& Matzuk MM 1998 Mouse models of ovarian failure. Reviews of Reproduction 3 183-195. (doi:10.1530/ror.0.0030183)

Fan HY, O'Connor A, Shitanaka M, Shimada M, Liu Z \& Richards JS 2010 $\beta$-Catenin (CTNNB1) promotes preovulatory follicular development but represses LH-mediated ovulation and luteinization. Molecular Endocrinology 24 1529-1542. (doi:10.1210/me.2010-0141)
Gougeon A 1996 Regulation of ovarian follicular development in primates: facts and hypotheses. Endocrine Reviews 17 121-155.

Guigon CJ \& Magre S 2006 Contribution of germ cells to the differentiation and maturation of the ovary: insights from models of germ cell depletion. Biology of Reproduction 74 450-458. (doi:10.1095/biolreprod.105. 047134)

Gundersen HJ 2002 The smooth fractionator. Journal of Microscopy 207 191-210. (doi:10.1046/j.1365-2818.2002.01054.x)

Harwood BN, Cross SK, Radford EE, Haac BE \& De Vries WN 2008 Members of the WNT signaling pathways are widely expressed in mouse ovaries, oocytes, and cleavage stage embryos. Developmental Dynamics 237 1099-1111. (doi:10.1002/dvdy.21491)

Hirshfield AN \& Midgley AR Jr 1978 The role of FSH in the selection of large ovarian follicles in the rat. Biology of Reproduction 19 606-611. (doi:10.1095/biolreprod19.3.606)

Hong H, Yen HY, Brockmeyer A, Liu Y, Chodankar R, Pike MC, Stanczyk FZ, Maxson R \& Dubeau L 2010 Changes in the mouse estrus cycle in response to BRCA1 inactivation suggest a potential link between risk factors for familial and sporadic ovarian cancer. Cancer Research 70 221-228. (doi:10.1158/0008-5472.CAN-09-3232)

Hsieh M, Johnson MA, Greenberg NM \& Richards JS 2002 Regulated expression of Wnts and Frizzleds at specific stages of follicular development in the rodent ovary. Endocrinology 143 898-908. (doi:10.1210/en.143.3.898)

Hsieh M, Mulders SM, Friis RR, Dharmarajan A \& Richards JS 2003 Expression and localization of secreted frizzled-related protein-4 in the rodent ovary: evidence for selective up-regulation in luteinized granulosa cells. Endocrinology 144 4597-4606. (doi:10.1210/en.20030048)

Hsieh M, Boerboom D, Shimada M, Lo Y, Parlow AF, Luhmann UF, Berger W \& Richards JS 2005 Mice null for Frizzled4 (Fzd4(-/-)) are infertile and exhibit impaired corpora lutea formation and function. Biology of Reproduction 73 1135-1146. (doi:10.1095/biolreprod.105. 042739)

Iglesias DM, Hueber PA, Chu L, Campbell R, Patenaude AM, Dziarmaga AJ, Quinlan J, Mohamed O, Dufort D \& Goodyer PR 2007 Canonical WNT signaling during kidney development. American Journal of Physiology. Renal Physiology 293 F494-F500. (doi:10.1152/ ajprenal.00416.2006)

Kim K, Pang KM, Evans M \& Hay ED 2000 Overexpression of $\beta$-catenin induces apoptosis independent of its transactivation function with LEF-1 or the involvement of major G1 cell cycle regulators. Molecular Biology of the Cell 11 3509-3523.

Kimura T, Nakamura T, Murayama K, Umehara H, Yamano N, Watanabe S, Taketo MM \& Nakano T 2006 The stabilization of $\beta$-catenin leads to impaired primordial germ cell development via aberrant cell cycle progression. Developmental Biology 300 545-553. (doi:10.1016/j. ydbio.2006.06.038)

Knight PG \& Glister C 2001 Potential local regulatory functions of inhibins, activins and follistatin in the ovary. Reproduction 121 503-512. (doi:10.1530/rep.0.1210503)

Krisher RL 2004 The effect of oocyte quality on development. Journal of Animal Science 82 (E-Suppl) E14-E23.

Logan CY \& Nusse R 2004 The Wnt signaling pathway in development and disease. Annual Review of Cell and Developmental Biology 20 781-810. (doi:10.1146/annurev.cellbio.20.010403.113126)

Marchal R, Vigneron C, Perreau C, Bali-Papp A \& Mermillod P 2002 Effect of follicular size on meiotic and developmental competence of porcine oocytes. Theriogenology 57 1523-1532. (doi:10.1016/S0093-691X(02) 00655-6)

Matzuk MM 2000 Revelations of ovarian follicle biology from gene knockout mice. Molecular and Cellular Endocrinology 163 61-66. (doi:10.1016/S0303-7207(99)00241-5)

McGee EA \& Hsueh AJ 2000 Initial and cyclic recruitment of ovarian follicles. Endocrine Reviews 21 200-214. (doi:10.1210/er.21.2.200)

Mermillod P, Dalbies-Tran R, Uzbekova S, Thelie A, Traverso JM, Perreau C, Papillier P \& Monget P 2008 Factors affecting oocyte quality: who is driving the follicle? Reproduction in Domestic Animals 43 (Suppl 2) 393-400. (doi:10.1111/j.1439-0531.2008.01190.x)

Miller JR 2002 The Wnts. Genome Biology 3 REVIEWS3001. 
Mohamed OA, Clarke HJ \& Dufort D $2004 \beta$-Catenin signaling marks the prospective site of primitive streak formation in the mouse embryo. Developmental Dynamics 231 416-424. (doi:10.1002/dvdy.20135)

Myers M, Britt KL, Wreford NG, Ebling FJ \& Kerr JB 2004 Methods for quantifying follicular numbers within the mouse ovary. Reproduction 127 569-580. (doi:10.1530/rep.1.00095)

Naillat F, Prunskaite-Hyyrylainen R, Pietila I, Sormunen R, Jokela T, Shan J \& Vainio SJ 2010 Wnt4/5a signalling coordinates cell adhesion and entry into meiosis during presumptive ovarian follicle development. Human Molecular Genetics 19 1539-1550. (doi:10.1093/hmg/ddq027)

Oakberg EF 1979 Follicular growth and atresia in the mouse. In Vitro 15 41-49. (doi:10.1007/BF02627078)

Ottolenghi C, Pelosi E, Tran J, Colombino M, Douglass E, Nedorezov T, Cao A, Forabosco A \& Schlessinger D 2007 Loss of Wnt4 and Foxl2 leads to female-to-male sex reversal extending to germ cells. Human Molecular Genetics 16 2795-2804. (doi:10.1093/hmg/ddm235)

Prieve MG \& Waterman ML 1999 Nuclear localization and formation of $\beta$-catenin-lymphoid enhancer factor 1 complexes are not sufficient for activation of gene expression. Molecular and Cellular Biology 19 4503-4515.

Richards JS 1994 Hormonal control of gene expression in the ovary. Endocrine Reviews 15 725-751.

Ricken A, Lochhead P, Kontogiannea M \& Farookhi R 2002 Wnt signaling in the ovary: identification and compartmentalized expression of wnt-2, wnt-2b, and frizzled-4 mRNAs. Endocrinology 143 2741-2749. (doi:10.1210/en.143.7.2741)

Takase K, Ishikawa M \& Hoshiai H 1995 Apoptosis in the degeneration process of unfertilized mouse ova. Tohoku Journal of Experimental Medicine 175 69-76. (doi:10.1620/tjem.175.69)
Vainio S, Heikkila M, Kispert A, Chin N \& McMahon AP 1999 Female development in mammals is regulated by Wnt-4 signalling. Nature 397 405-409. (doi:10.1038/17068)

Wang QT, Piotrowska K, Ciemerych MA, Milenkovic L, Scott MP, Davis RW \& Zernicka-Goetz M 2004 A genome-wide study of gene activity reveals developmental signaling pathways in the preimplantation mouse embryo. Developmental Cell 6 133-144. (doi:10.1016/S15345807(03)00404-0)

Wang Y, van der Zee M, Fodde R \& Blok LJ 2010 Wnt/ $\beta$-catenin and sex hormone signaling in endometrial homeostasis and cancer. Oncotarget 1 674-684.

Wodarz A \& Nusse R 1998 Mechanisms of Wnt signaling in development. Annual Review of Cell and Developmental Biology 14 59-88. (doi:10.1146/annurev.cellbio.14.1.59)

Yao HHC, Matzuk MM, Jorgez CJ, Menke DB, Page DC, Swain A \& Capel B 2004 Follistatin operates downstream of Wnt4 in mammalian ovary organogenesis. Developmental Dynamics 230 210-215. (doi:10.1002/ dvdy.20042)

Zheng P, Vassena R \& Latham K 2006 Expression and downregulation of WNT signaling pathway genes in rhesus monkey oocytes and embryos. Molecular Reproduction and Development 73 667-677. (doi:10.1002/ mrd.20428)

Received 26 July 2012

First decision 6 September 2012

Accepted 24 September 2012 